\title{
EMLA cream is an effective topical anesthetic for bronchoscopy
}

\author{
Benjamin Sohmer MD ${ }^{1}$, Gregory L Bryson MD FRCPC ${ }^{1}$, Steven Bencze MD FRCPC ${ }^{2}$, \\ Maria Mouroukas Scharf RRCP ${ }^{3}$
}

B Sohmer, GL Bryson, S Bencze, MM Scharf. EMLA cream is an effective topical anesthetic for bronchoscopy. Can Respir J 2004;11(8):587-588.

BACKGROUND: EMLA cream (AstraZeneca Inc, Canada) (1:1 eutectic mixture of lidocaine $2.5 \%$ and prilocaine $2.5 \%$ ) has traditionally been used for topical anesthesia of the skin. Recent reports of EMLA's use for anesthesia of the oral mucosa suggest an application in topical anesthesia for bronchoscopy.

OBJECTIVES: To evaluate the amount of local anesthetic administered during bronchoscopy; to assess the time required to obtain topical anesthesia; to assess the quality of the topical anesthesia as described by bronchoscopists; and to document any complications.

METHODS: Fifty-seven unpremedicated patients had $4 \mathrm{~mL}$ of EMLA cream applied to the posterior third of their tongues on arrival in the bronchoscopy suite. Liquid lidocaine was applied through the bronchoscope for laryngeal anesthesia.

RESULTS: The mean time from the application of EMLA cream to insertion of the bronchoscope was $5.10 \pm 0.48 \mathrm{~min}$. Fifty-six patients (98.2\%) required no supplemental anesthesia. Bronchoscopy conditions were described as 'excellent' in 55 cases $(96.5 \%)$ and 'good' in the remaining two cases $(3.5 \%)$.

CONCLUSIONS: EMLA is an effective alternative for oropharyngeal topical anesthesia that is well-tolerated by patients.

Key Words: Administration; Anesthesia; Bronchoscopy; EMLA; Lidocaine; Local; Prilocaine; Topical

\section{La crème EMLA est un anesthésique topique efficace pour la bronchoscopie}

\begin{abstract}
HISTORIQUE : La crème EMLA (AstraZeneca Inc., Canada) (1:1 mélange eutectique de lidocaïne 2,5\% et de prilocaïne 2,5\%) a toujours été utilisée comme anesthésique topique de la peau. Les comptes rendus récents sur l'usage de l'EMLA pour l'anesthésie de la muqueuse orale suggèrent une application pour l'anesthésie topique de la bronchoscopie. OBJECTIFS : Évaluer la quantité d'anesthésique locale administré pendant la bronchoscopie, évaluer le temps nécessaire pour obtenir une anesthésie topique, évaluer la qualité de l'anesthésie topique décrite par les bronchoscopistes et documenter les complications.

MÉTHODOLOGIE : Cinquante-sept patients qui n'avaient pas pris de médicaments auparavant se sont fait appliquer $4 \mathrm{~mL}$ de crème EMLA sur le tiers postérieur de la langue à leur arrivée au local de bronchoscopie. De la lidocaïne liquide a été appliquée au moyen du bronchoscope pour assurer l'anesthésie du larynx.

RÉSULTATS : Le temps moyen entre l'application de la crème EMLA et l'insertion du bronchoscope était de 5,10 $\pm 0,48 \mathrm{~min}$. Cinquante-six patients $(98,2 \%)$ n'ont pas eu besoin d'anesthésie supplémentaire. Les conditions de bronchoscopie ont été décrites comme " excellentes » dans 55 cas $(96,5 \%)$ et de « bonne » dans les deux autres cas $(3,5 \%)$.

CONCLUSIONS : La crème EMLA est une solution efficace pour l'anesthésie oropharyngée, et elle est bien tolérée des patients.
\end{abstract}

A nesthesia of the oropharyngeal airway before bronchoscopy is required to minimize the gag reflex and coughing, and to facilitate a comfortable, yet thorough, evaluation of the patient's airway. Local anesthetics have been sprayed, aerosolized, atomized and applied as a viscous gel to achieve topical anesthesia of the oropharynx $(1,2)$. These techniques, although effective, are limited by the ease of application, time required, amount of local anesthetic used and patient discomfort.

EMLA cream (AstraZeneca Inc, Canada) is a 1:1 eutectic mixture of lidocaine $2.5 \%$ and prilocaine $2.5 \%$. Both lidocaine and prilocaine are amide-type local anesthetics and function by preventing the initiation and conduction of nerve impulses. The depth of anesthesia is dependent on the dose of the drug and its time of application. Absorption, onset and duration of anesthesia with EMLA will vary based on blood flow, thickness and pathology of the tissue to which it is applied. Traditional indications for the use of EMLA include topical anesthesia for venipuncture (3), laser excision of condylomata (4) and dressing changes (5). The safe use of EMLA for topical anesthesia of the oral mucosa has also been described $(6,7)$.

Clinicians at The Ottawa Hospital (Ottawa, Ontario) have recently adopted EMLA cream for oropharyngeal anesthesia. The purpose of the present study was to evaluate the use of EMLA cream for topical anesthesia of the oropharyngeal mucosa for diagnostic bronchoscopy.

\section{MATERIALS AND METHODS}

After The Ottawa Hospital research ethics board approval, the charts of 57 consecutive patients (both inpatients and outpatients) that underwent diagnostic bronchoscopy using EMLA for oropharyngeal topical anesthesia were reviewed retrospectively. All patients arrived in the bronchoscopy suite with intravenous access. No premedication or supplemental intravenous sedation were administered. Oxygen was applied to patients via nasal prongs at $3 \mathrm{~L} / \mathrm{min}$. Three-lead electrocardiography and oxygen saturation monitors were applied. EMLA cream (4 mL; $100 \mathrm{mg}$ lidocaine and $100 \mathrm{mg}$ prilocaine) was dispensed into a disposable syringe. Patients were asked to open their mouths with their tongues extended and the cream was applied all at once to the posterior third of the tongue. The cream became less viscous as it mixed with 
TABLE 1

Patient characteristics and local anesthetic consumption $(n=57)$

\begin{tabular}{lc}
\hline Male:female & $29: 28$ \\
Age $^{*}$ (years) & $59.5 \pm 15.0$ \\
EMLA cream $^{\dagger}$ applied $^{*}(\mathrm{~mL})$ & $4.0 \pm 0.07$ \\
Total local anesthetic administered* $(\mathrm{mg})$ & $280.8 \pm 16.8$ \\
\hline
\end{tabular}

${ }^{*}$ Results expressed as mean $\pm S D ;{ }^{\dagger}$ AstraZeneca Inc, Canada

saliva. Patients were encouraged to mix and gargle the cream within their oropharynx. Bronchoscopists then gowned, gloved and positioned patients for the procedure. The time from initial EMLA cream application to insertion of bronchoscope was recorded. Patients were asked to expel any remaining oral contents before bronchoscope insertion. For dose calculation purposes, it was assumed that no remaining contents were expelled and the maximal mass of administered drug was recorded. All bronchoscopies were performed orally. On visualization of the larynx, liquid lidocaine was applied through the bronchoscope for laryngeal anesthesia. Adequacy of anesthesia (excellent, fair, good or poor), need for supplemental airway anesthesia, the amount of liquid lidocaine used for laryngeal anesthesia and procedural complications were recorded.

\section{RESULTS}

Fifty-seven consecutive patients received topical oral airway anesthesia with EMLA cream. Indications for bronchoscopy were varied and not recorded. Patients ranged in age from 28 to 91 years and their characteristics are described in Table 1. The mass of lidocaine administered at the larynx was $79.65 \pm 14.39 \mathrm{mg}$. Bronchoscopy conditions were described as 'excellent' in 55 cases $(96.5 \%)$ and 'good' in the remaining two cases $(3.5 \%)$. Supplemental oral anesthesia, in the form of four sprays of $2 \%$ lidocaine spray, was administered to the oropharynx in one case $(1.8 \%)$. The remaining 56 cases $(98.2 \%)$ required no supplementation. The total mass of local anesthetic administered (prilocaine in EMLA, lidocaine in EMLA, laryngeal topical lidocaine and supplemental lidocaine spray) was $280.8 \pm 16.8 \mathrm{mg}$ (range $240 \mathrm{mg}$ to $345 \mathrm{mg}$ ). The mean time from the application of EMLA cream to insertion of the bronchoscope was $5.10 \pm 0.48 \mathrm{~min}$.

\section{DISCUSSION}

The scope of EMLA cream's use is slowly expanding and now includes a recent report (8) of its use for awake fibre optic endoscopy and oral endotracheal intubation. To date, we have not found any published literature describing EMLA cream use in diagnostic bronchoscopy. Bronchoscopy is an invasive procedure commonly performed on an outpatient basis that requires adequate airway anesthesia and patient compliance to be successful. Inadequate analgesia may lead to repeated doses of local anesthetics, narcotic analgesia or sedative hypnotics. Seizures and airway obstruction following repeated attempts to provide analgesia for bronchoscopy have been reported $(9,10)$.

A $400 \mathrm{mg}$ total dose limit of lidocaine is presently recommended for fibre optic bronchoscopy (11). Much of this mass (approximately 75\%) is often used for oropharyngeal anesthesia alone. With the requirement of tracheobronchial anesthesia, the likelihood of toxic lidocaine dose administration increases $(10,12)$. It may be difficult to account for local anesthetics applied when nebulizers, tonsil tip sprays and gargles are used. In the present study, every milligram of local anesthetic was accounted for ( $70 \%$ of recommended maximum), decreasing the likelihood of accidental toxic administration. Previous reports (8) showed that with oral mucosa administration of $4 \mathrm{~mL}$ of EMLA, the peak plasma concentration of both lidocaine and prilocaine did not reach toxic levels (8). As well, methemoglobin levels did not exceed normal values, which is of concern with prilocaine administration (8).

Anxiolysis and amnesia are two indications for supplemental intravenous medication during bronchoscopy. It is the gag and choke experience, often the most unpleasant aspect, that requires amnesia. It can be argued that much of patient anxiety stems from the unpleasant 'freezing' portion of the procedure. Patients have characterized EMLA as being the least unpleasant method of airway topicalization (13). We achieved simple, pleasant and effective topical anesthesia that blunted any significant gag reflex. This, in turn, should decrease requirements for additional intravenous sedation, reducing the risk of excess sedation and respiratory depression. Our cohort did not require any supplemental intravenous sedation.

The present study has shown EMLA cream to be an alternative for oropharyngeal topical anesthesia that is effective and well-tolerated by patients, and which decreases the overall mass of local anesthetic required for successful bronchoscopy.

\section{REFERENCES}

1. Isaac PA, Barry JE, Vaughan RS, Rosen M, Newcombe RG. A jet nebuliser for delivery of topical anesthesia to the respiratory tract. A comparison with cricothyroid puncture and direct spraying for fibreoptic bronchoscopy. Anaesthesia 1990;45:46-8.

2. Webb AR, Woodhead MA, Dalton HR, Grigg JA, Millard FJ. Topical nasal anaesthesia for fibreoptic bronchoscopy: Patients' preference for lignocaine gel. Thorax 1989;44:674-5.

3. Fetzer SJ. Reducing venipuncture and intravenous insertion pain with eutectic mixture of local anesthetic: A meta-analysis. Nurs Res 2002;51:119-24.

4. Rylander E, Sjoberg I, Lillieborg S, Stockman O. Local anesthesia of the genital mucosa with a lidocaine/prilocaine cream (EMLA) for laser treatment of condylomata acuminata: A placebo-controlled study. Obstet Gynecol 1990;75:302-6.

5. Briggs M, Nelson EA. Topical agents or dressings for pain in venous leg ulcers. Cochrane Database Syst Rev 2003;(1):CD001177.

6. McMillan AS, Walshaw D, Meechan JG. The efficacy of Emla and $5 \%$ lignocaine gel for anaesthesia of human gingival mucosa. Br J Oral Maxillofac Surg 2000;38:58-61.

7. Vickers ER, Marzbani N, Gerzina TM, McLean C, Punnia-Moorthy A, Mather L. Pharmacokinetics of EMLA cream 5\% application to oral mucosa. Anesth Prog 1997;44:32-7.

8. Larijani GE, Cypel D, Gratz I, et al. The efficacy and safety of EMLA cream for awake fiberoptic endotracheal intubation. Anesth Analg 2000;91:1024-6.

9. McGuire G, el-Beheiry H. Complete upper airway obstruction during awake fibreoptic intubation in patients with unstable cervical spine fractures. Can J Anaesth 1999;46:176-8.

10. Wu FL, Razzaghi A, Souney PF. Seizure after lidocaine for bronchoscopy: Case report and review of the use of lidocaine in airway anesthesia. Pharmacotherapy 1993;13:72-8.

11. National Institutes of Health workshop summary. Summary and recommendations of a workshop on the investigative use of fiberoptic bronchoscopy and bronchoalveolar lavage in individuals with asthma. J Allergy Clin Immunol 1985;76:145-7.

12. Langmack EL, Martin RJ, Pak J, Kraft M. Serum lidocaine concentrations in asthmatics undergoing research bronchoscopy. Chest 2000;117:1055-60.

13. Randell T, Yli-Hankala A, Valli H, Lindgren L. Topical anaesthesia of the nasal mucosa for fibreoptic airway endoscopy. Br J Anaesth 1992;68:164-7. 


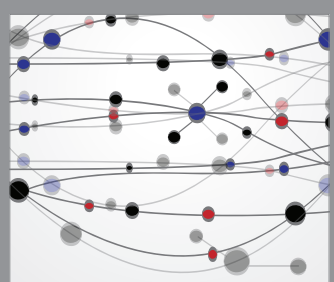

The Scientific World Journal
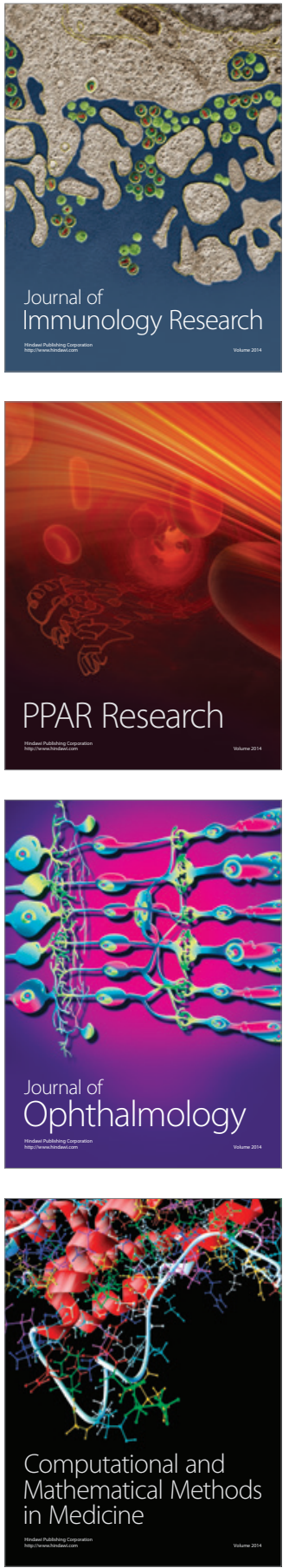

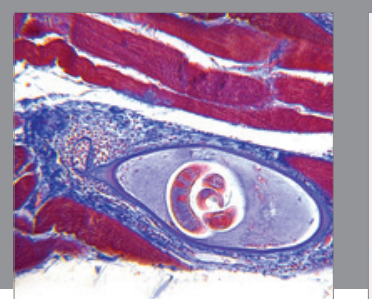

Gastroenterology Research and Practice

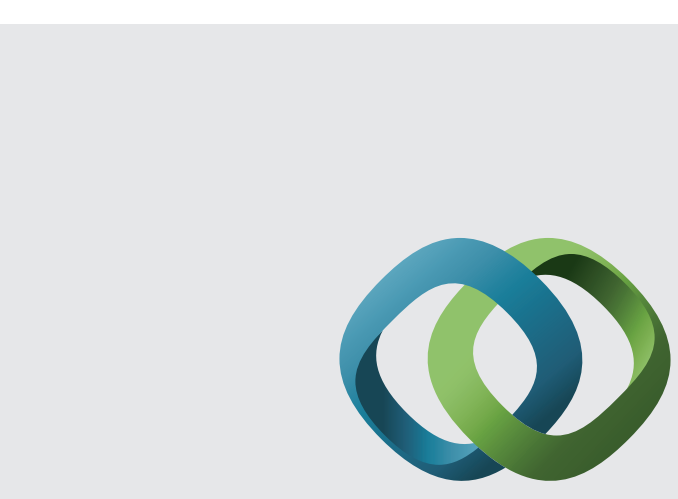

\section{Hindawi}

Submit your manuscripts at

http://www.hindawi.com
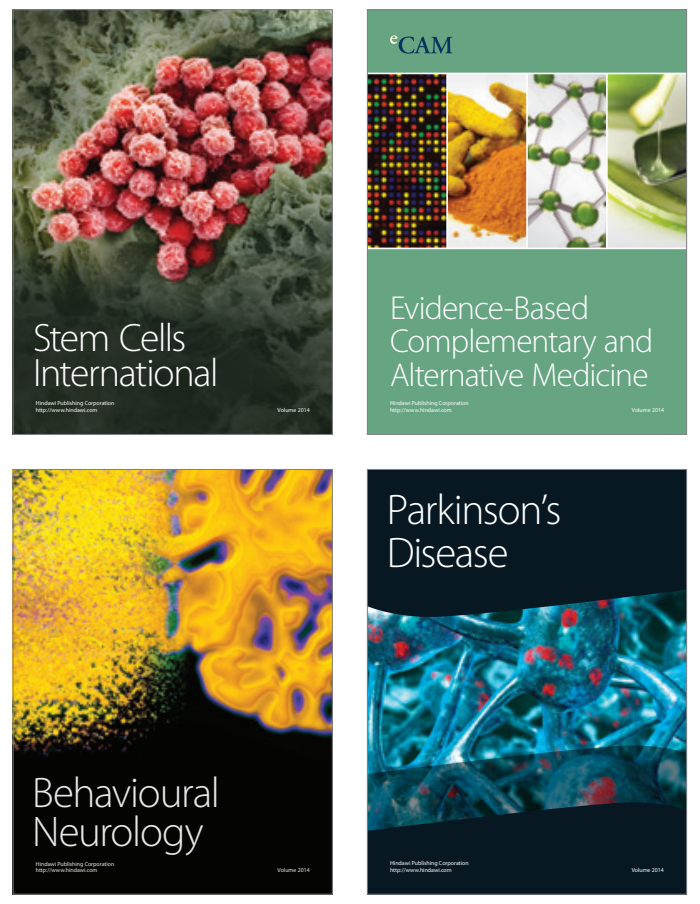
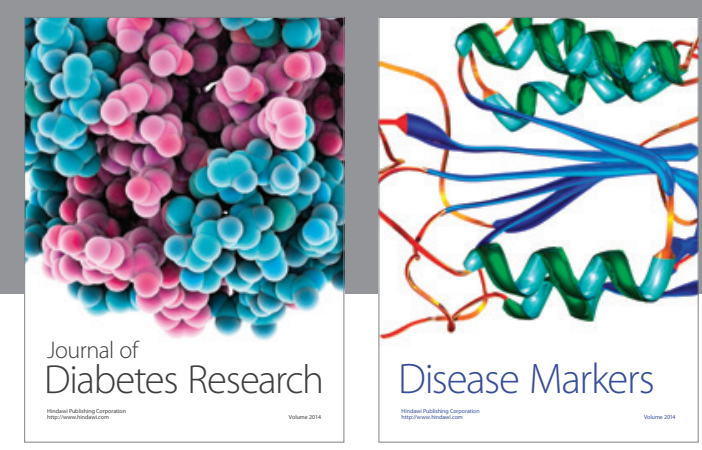

Disease Markers
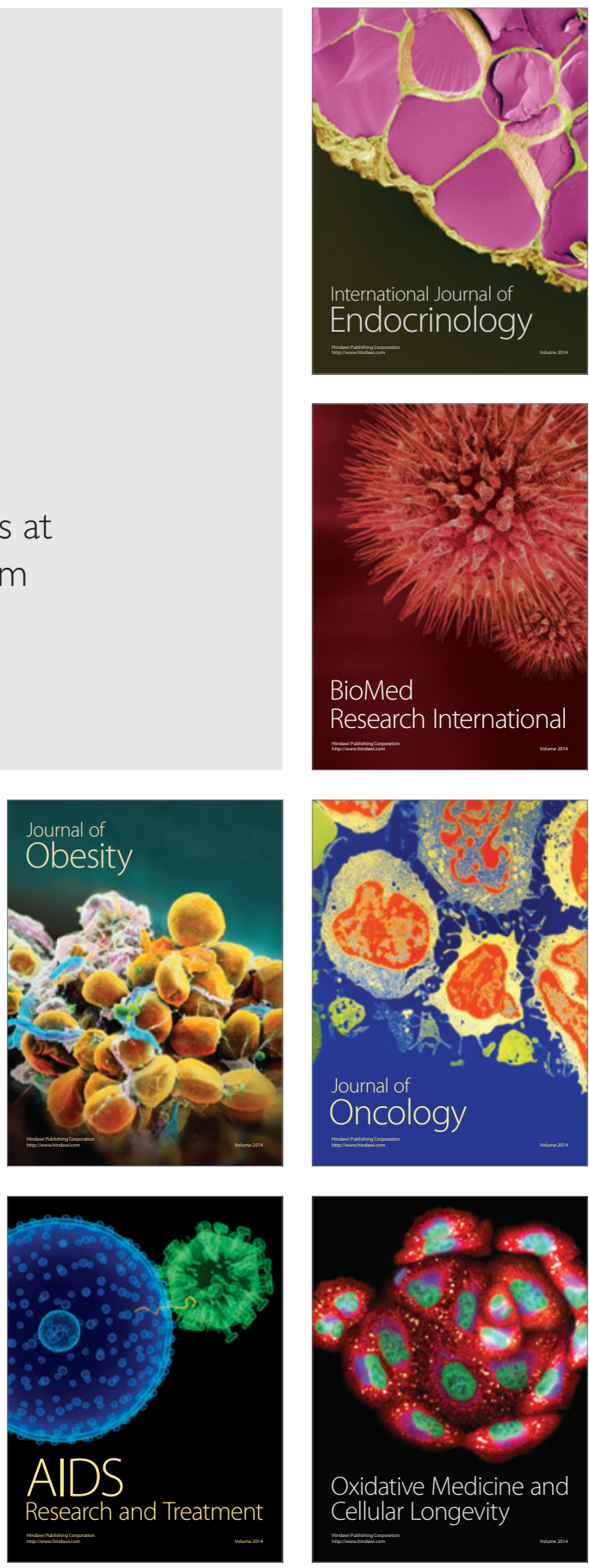